\title{
Post-operative pain prevalence, predictors, management practices and satisfaction among operated cases at a Regional Referral Hospital in Dar es Salaam, Tanzania
}

MASUMBUKO Y. MWASHAMBWA, ISAYA M. YONGOLO, SECILIA N. KAPALATA and ALFRED J. MEREMO

School of Medicine \& Dentistry, College of Health Sciences, The University of Dodoma, P.O Box 395, Dodoma, Tanzania

\begin{abstract}
Background: Post-operative pain is an essential component of good surgical patient care plan. In developing countries however, the prevalence of post-operative pain is relatively very high and pain control strategies are not very promising. The objective of this study was to assess post-operative pain prevalence, predictors, management practices and satisfaction among operated cases at a regional referral hospital in Dar es Salaam, Tanzania.

Methods: Prospective hospital based descriptive observational study of operated cases at a Temeke Regional Referral Hospital in Dar es Salaam, Tanzania. Data was collected using a pre-constructed questionnaire and a visual pain intensity scale.

Results: A total of 136 patients were recruited with mean age of $37.1 \pm 15$ years (range $=14-80$ years). The prevalence of pain was $100 \%, 83.9 \%$, and $36 \%$ at 12,24 and 48 hours, respectively. At 12 hours moderate to worst pain was reported in $95.6 \%$ of cases. The main prediction factor for severe to worst pain at 12 hours was orthopaedic procedures $(p=0.05, A O R=3.456)$, while widow/divorced marital status and female sex were negatively correlated to severity of pain $(p=0.005, A O R=0.0230$ and $p=0.000, A O R=0.034$, respectively). The commonest drugs prescribed post-operatively were injection pethidine $(50.5 \%)$ and tramadol (48.9\%) and oral tramadol (47.6\%). Pain management satisfaction rate was paradoxically high (74.3\%), with male sex being the main predictor.

Conclusion: The prevalence of early post-operative pain is very high. Male sex and orthopaedic procedures are associated with severe pain. Surgeons therefore need to prioritize analgesic prescription at early hours following operation to minimize pain and suffering to patients focusing on orthopaedic procedures.
\end{abstract}

Keywords: post-operative pain, prevalence, predictors, pain management, satisfaction, Tanzania

\section{Introduction}

Post-operative pain is an essential component of surgical patient care plan. Unrelieved pain is unnatural, inhumane, and immunosuppressive, and it is associated with both local wound and systemic complications (Ramsay, 2000; Lennard et al., 2006). Reported complications include delayed wound healing, transition to chronic pain, reduced vital capacity and alveolar ventilation, pneumonia, deep vein thrombosis, hypertension, myocardial ischemia and infarction (Breivik, 1998; Carr \& Goudas, 1999; Ramsay, 2000). Good pain relief allows early mobilization and fast recovery; it reduces hospital stay and costs and indeed a comfort to surgeons (Ramsay, 2000; Apfelbaum et al., 2003). This is to say, inadequately controlled pain negatively affects quality of life, functional recovery and risks post-surgical complications and persistent pain (Kehlet et al., 2006).

Globally, the prevalence of post-operative pain varies among studies. The American Pain Society suggests a prevalence of more than $80 \%$, with three quarters (75\%) reporting moderate to severe pain and less than half reporting good pain relief (Apfelbaum et al., 2003; Gagliese et al., 2005). Thomas et al. (1998) in Australia reported better pain control and patients satisfaction while in Denmark the prevalence of moderate to severe pain was found to be $45.5 \%$ at 24 hours with satisfaction rate of $88.4 \%$ (Lorentzen et al., 2012). In the United Kingdom one study reported a prevalence of moderate to severe pain and very severe pain to be $29.7 \%$ and $10.9 \%$ respectively with lower incidence of poor pain relief (at 3.5\%) and fair-to-poor pain relief at 19.4\%, with the use of injectable analgesia resulted in poorest pain control (67.2\%) than patients controlled analgesia (35.8\%) and epidural analgesia (20.9\%) (Dolin et al., 2002). There are fewer studies in developing countries; most indicate high prevalence of post-operative pain with unfavourable relief. Uganda 
has the highest prevalence (over 90\%) as reported by Mbula (2010). In Tanzania a prevalence of some form of pain was $85.5 \%$ and $77.4 \%$ at 24 and 48 hours respectively, in a recent study by Masagati \& Chilonga (2014).

The most common predictors of severe pain reported include female sex, young age, high pre-operative pain severity, drug type and route of administration (Thomas et al., 1998; Masagati \& Chilonga, 2014). Others include high anxiety about risks and problems, low expected pain severity, young age and high willingness to report pain (Thomas et al, 1998). As part of effective management of post-operative pain, experts recommends use of multimodal strategies including preoperative, intra operative, and postoperative interventions, thorough evaluation of patients, involvement of all parties and individualized, the so called "patient-centred therapies" (Chou et al., 2016).

Studies of pain relief practices in regional hospitals in Tanzania are scanty and possibly not adequately conducted despite that there is high prevalence coupled with repeated management inadequacies. This study was conducted to assess prevalence, predictors, management practices and satisfaction of post-operative pain among operated patients at a regional referral hospital in Tanzania.

\section{Materials and Methods}

\section{Study area, design and population}

This was a prospective hospital based descriptive observational study conducted at Temeke Regional Referral Hospital in Dar es Salaam, Tanzania. According to the National Bureau of Statistics (URT, 2013), the hospital serves approximately 1.4 million people. The hospital has a bed capacity of 230, with surgical wards having 45 beds.

The study included all patients of both sexes older than 13 years of age admitted in surgical wards and who underwent major general and orthopaedic operations from August $28^{\text {th }}$ to October $28^{\text {th }}$ 2015. All patients who underwent general surgery and orthopaedic procedures were conveniently recruited into the study for a period of two month from August $28^{\text {th }}$ to October $28^{\text {th }}$ 2015. Patients with severe trauma, neurological deficits and who were unconscious or subconscious were excluded from this study.

\section{Data collection}

A standardized Kiswahili translated questionnaires was used, pain was assessed at 12, 24 and 48 hours post operatively using a visual pain intensity scale (Bijur et al., 2003). Patients were asked to read and score the pain on a scale ranging from no pain to worst possible pain.

\section{Data analysis}

Collected data was cleaned and entered into IBM SPSS version 20 statistical software for analysis. Data was summarized into frequency and proportions tables. Binary logistic analysis was used to assess correlation between dependent and independent variables. A p value of 0.05 was used to indicate significant correlation at $95 \%$ confidence interval.

\section{Ethical considerations}

The permission to conduct this study was obtained from an ethical committee of the University of Dodoma, and the office of Temeke District Medical Officer through Medical Officer In charge of the hospital. A written consent was obtained from all patients recruited in the study, and for participants younger than 18 years the consent was obtained from their guardians.

\section{Results}

\section{Demographic characteristics}


A total of 136 patients who underwent major operations at the hospital were purposefully recruited. The mean age was 37.1 years with a range of $14-80$ years and standard deviation of 15 . Majority of patients were married ( $64.7 \%), 43.4 \%$ had secondary education, and a large proportion were either self-employed or doing business (40.4\%) (Table 1).

Table 1: Socio-demographic characteristics of the patients

\begin{tabular}{|c|c|c|c|c|}
\hline Status & Category & Male $(\mathrm{N}=71)$ & Female $(\mathrm{N}=65)$ & Total \\
\hline \multirow{3}{*}{ Age } & $<20$ & $8(66.7 \%)$ & $4(33 \cdot 3 \%)$ & $12(8.8 \%)$ \\
\hline & $21-40$ & $36(46.8 \%)$ & $41(53.2 \%)$ & $77(56.6 \%)$ \\
\hline & $>40$ & $27(57.5 \%)$ & $20(42.5 \%)$ & $47(34.6 \%)$ \\
\hline \multirow{4}{*}{ Marital status } & Not married & $20(87 \%)$ & $3(13 \%)$ & $23(16.9 \%)$ \\
\hline & Married & $41(46.6 \%)$ & $47(53.4 \%)$ & $88(64.7 \%)$ \\
\hline & Widowed & $8(50 \%)$ & $8(50 \%)$ & $16(11.8 \%)$ \\
\hline & Cohabited & $2(22.2 \%)$ & $7(77.8 \%)$ & $9(6.6 \%)$ \\
\hline \multirow{4}{*}{ Education level } & No formal education & $10(50 \%)$ & $10(50 \%)$ & $20(15.4 \%)$ \\
\hline & Primary & $21(48.8 \%)$ & $22(51.2 \%)$ & $43(31.6 \%)$ \\
\hline & Secondary & $30(50.8 \%)$ & $29(49.2)$ & $59(43.4 \%)$ \\
\hline & College/university & $10(71.4 \%)$ & $4(28.6 \%)$ & $14(10.3 \%)$ \\
\hline \multirow{4}{*}{ Employment } & Unemployed & $17(40.5 \%)$ & $25(59.5 \%)$ & $42(30.9 \%)$ \\
\hline & Employed & $15(53.6 \%)$ & $13(46.4)$ & $28(20.6 \%)$ \\
\hline & Farmer/peasant & $7(63.6 \%)$ & $4(36.4 \%)$ & $11(8.1 \%)$ \\
\hline & $\begin{array}{l}\text { Business/self } \\
\text { employed }\end{array}$ & $32(58.2 \%)$ & $23(31.8 \%)$ & $55(40.4 \%)$ \\
\hline
\end{tabular}

The prevalence of some form of pain among patients who were operated was $100 \%, 83.9 \%$, and $36 \%$ at 12, 24 and 48 hours, respectively. Moderate to worst pain was reported among $95.6 \%$ of the patients at 12 hours, $32.4 \%$ at 24 hours, and only $5 \%$ at 48 hours. About $64 \%$ of patients were pain free at $48 \%$ (Table 2 ).

Table 2: Prevalence of post-operative pain by time of assessment

\begin{tabular}{lccccccc}
\hline Time & \multicolumn{7}{c}{ Degree of pain } \\
& No pain & Mild & Moderate & Severe & Very severe & Worst & Total \\
\hline 12 hours & 0 & $6(4.4 \%)$ & $59(43.4 \%)$ & $30(22.1 \%)$ & $35(25.7 \%)$ & $6(4.4 \%)$ & 136 \\
24 hours & $22(16.2 \%)$ & $70(51.5 \%)$ & $30(22.1)$ & $14(10.3 \%)$ & 0 & 0 & 136 \\
48 hours & $87(64 \%)$ & $42(31 \%)$ & $7(5 \%)$ & 0 & 0 & 0 & 136 \\
\hline
\end{tabular}

\section{Predictors of severe to worst pain}

The correlation between severe to worst pain at 12 and 24 hours and patients' demographic characteristics, type of procedure and anaesthesia as independent variables were assessed using a binary logistic analysis. Patients who were widowed or divorced (as a group) were less likely to get severe to worst pain at 12 hours [ $=0.005$, Adjusted Odds Ratio $(A O R)=0.023$, the same association was not observed at 24 hours. This findings was also observed in females ( $p=0.000$, $A O R=0.034)$ than males. Orthopaedic procedures were found to be associated with severe to worst pain $(p=0.05, A O R=3.456)$. Although not significant, young patients were less likely to get severe to worst pain. A similar observation was made among college/university education, peasants/farmers and those operated under general anaesthesia (Table 3). 
Table 3: Predictors of post-operative pain

\begin{tabular}{|c|c|c|c|c|c|c|c|c|c|}
\hline \multirow{2}{*}{$\begin{array}{l}\text { Pain at } 12 \text { hours } \\
\text { Covariates } \\
\text { Education level }\end{array}$} & \multicolumn{9}{|c|}{ Pain at 24 hours } \\
\hline & AOR & P-value & \multicolumn{2}{|c|}{$\begin{array}{l}\text { 95\% Confidence } \\
\text { Interval }\end{array}$} & Covariates & AOR & $\begin{array}{c}\mathrm{P} \text { - } \\
\text { value }\end{array}$ & \multicolumn{2}{|c|}{$95 \%$ C.I } \\
\hline No education & 1 & & & & No education & 1 & & & \\
\hline Primary & 3.145 & 0.247 & 0.453 & 21.84 & Primary & 0.926 & 0.923 & 0.193 & 4.446 \\
\hline Secondary & 2.822 & 0.301 & 0.395 & 20.17 & Secondary & 1.245 & 0.778 & 0.271 & 5.718 \\
\hline College & 4.183 & 0.317 & 0.253 & 69.05 & College & 1.299 & 0.82 & 0.136 & 12.43 \\
\hline \multicolumn{10}{|l|}{ Marital status } \\
\hline Not married & 1 & & & & Not married & 1 & & & \\
\hline Married & 0.314 & 0.224 & 0.049 & 2.032 & Married & 1.274 & 0.727 & 0.074 & 1.376 \\
\hline Widow & 0.023 & 0.005 & 0.002 & 0.317 & Widow & 0.21 & 0.145 & 0.068 & 3.111 \\
\hline Cohabiting & 0.096 & 0.137 & 0.004 & 2.106 & Cohabiting & 0.399 & 0.515 & 0.008 & 1.907 \\
\hline \multicolumn{10}{|l|}{ Employment } \\
\hline Unemployed & 1 & & & & Unemployed & 1 & & & \\
\hline Employed & 0.753 & 0.756 & 0.126 & 4.495 & Employed & 0.73 & 0.7 & 0.147 & 3.619 \\
\hline Farmer & 3.250 & 0.309 & 0.335 & 31.52 & Farmer & 0.546 & 0.561 & 0.071 & 4.189 \\
\hline Business & 0.550 & 0.407 & 0.134 & 2.258 & Business & 0.541 & 0.369 & 0.141 & 2.069 \\
\hline \multicolumn{10}{|l|}{ Type of surgery } \\
\hline General & 1 & & & & General & 1 & & & \\
\hline Orthopaedic & 3.456 & 0.050 & 0.998 & 11.968 & Orthopaedic & 1.612 & 0.421 & 0.505 & 5.148 \\
\hline \multicolumn{10}{|c|}{ Type of anaesthesia } \\
\hline Regional & 1 & & & & Regional & 1 & & & \\
\hline $\begin{array}{l}\text { General } \\
\text { Sex }\end{array}$ & 1.459 & 0.551 & 0.422 & 5.051 & General & 1.025 & 0.964 & 0.344 & 3.053 \\
\hline Male & 1 & & & & Male & 1 & & & \\
\hline Female & 0.034 & 0.000 & 0.010 & 0.114 & Female & 0.048 & 0.000 & 0.013 & 0.176 \\
\hline Age & 0.006 & 0.925 & 0.875 & 0.978 & Age & 0.596 & 0.987 & 0.938 & 1.037 \\
\hline \multicolumn{10}{|c|}{1 = reference category } \\
\hline
\end{tabular}

\section{Prescription pattern}

The commonest drugs prescribed postoperatively were in the first day injectable pethidine and tramadol (50.4\% and $48.9 \%$, respectively). During the second day injectable tramadol was the commonest (48.4\%) followed by oral tramadol (47.6\%). Oral tramadol was prescribed in $83.1 \%$ patients after 48 hours (Figure 2). 


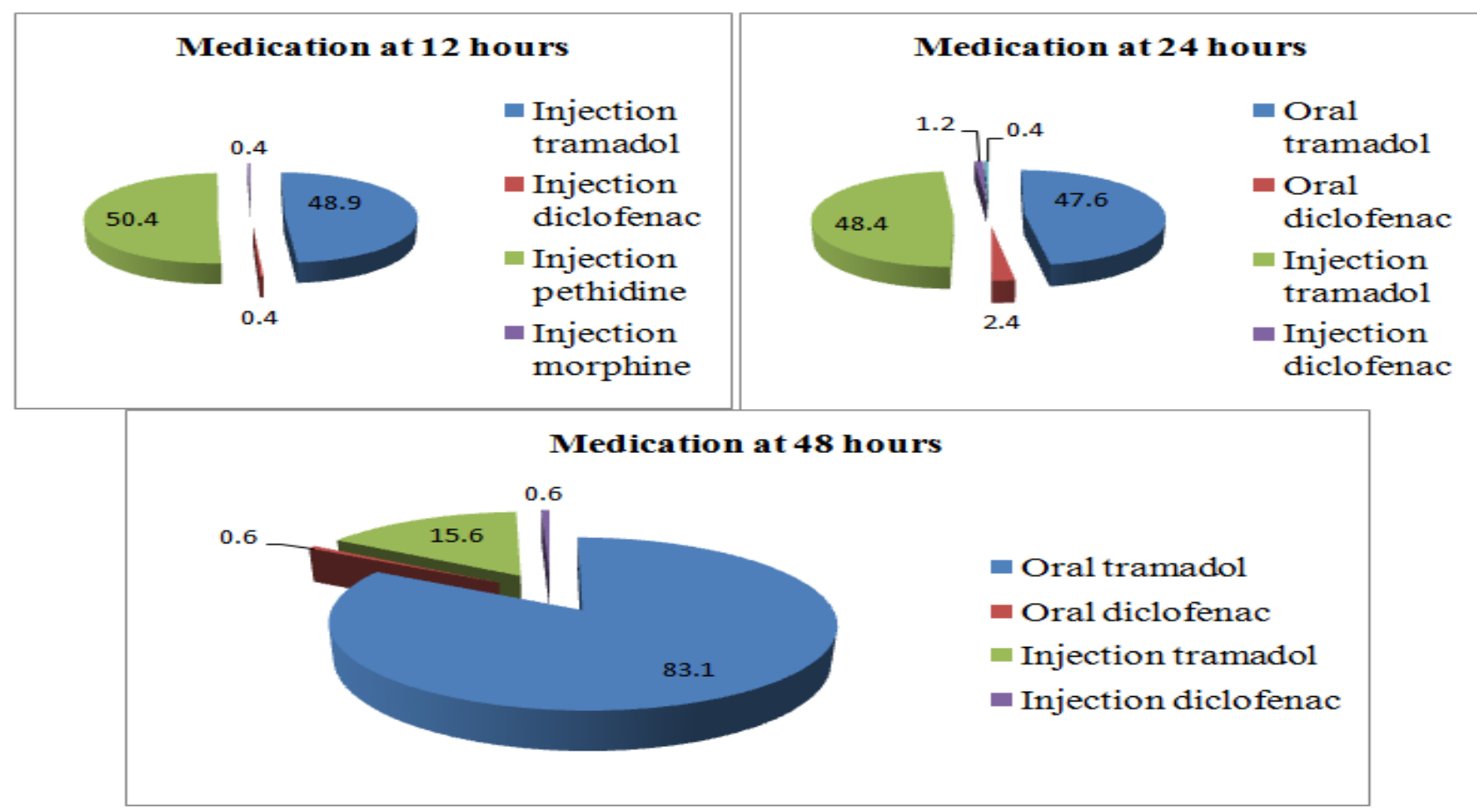

Figure 2: Percentage frequency distribution of common prescribed drugs

\section{Patients' satisfaction on pain management}

Of all patients who were assessed on satisfaction of pain management at twelve hours, $74.3 \%$ reported that they were satisfied with pain management provided. Male patients were almost 30 times more likely to be satisfied with pain management provided than females $(p=.000, A O R=$ 29.814). The rest of independent variables had no significant correlation, although primary and secondary education had twice as much odd on satisfaction. Almost three quarters of patients were satisfied with treatment they were given.

\section{Discussion}

In this study it has been found that the prevalence of acute postoperative pain is very high, it is $100 \%$ at 12 hours. The prevalence pain at 12 hours in our study was higher than that reported in most studies (Ramsey, 2000; Chung \& Lui, 2003; Mbula, 2010; Misagati \& Chilonga, 2014) and slightly similar to that reported by Bagi \& Ahmed (1993) in Sudan. The observed difference could be explained by the fact that data collection was done at an earlier time than previous studies which collected data after 24 hours. This is further proven by the similarity of prevalence of pain at 24 hours. In the our study, there was lower prevalence of pain at 48 hours contrary to findings of other studies (Gan et al., 2014; Misagati \& Chilonga, 2014). The observed difference could be explained by methodological differences between the studies. Gan et al. (2014) did a community survey of individuals who were operated within five years but not within the immediate postoperative period like in our study, while Misagati \& Chilonga (2014) did their study within the postoperative period similar to our current study. However they assessed pain at rest, during movement, changing position and during physiotherapy. This could have affected pain perception and possibly aggravated pain. In our assessment, pain was assessed with no regard to movements.

In this study at 12 hours a negative correlation was observed among patients who were widowed or divorced. The patients in this category were less likely to experience severe to worst pain than the reference group (not married). At 24 hours this relationship still existed but wasn't statistically significant. One community-based study reported a significant association between divorced or widow with body pain intensity (Xu et al., 2016). No simple explanation could be given 
on this observation but it may be speculated that divorced or widowed have possibly endured a lot in their lives which may have increased their pain threshold, but further studies are required to explore this phenomenon.

It has been demonstrated that at 12 and 24 hours orthopaedic procedures are more painful than soft tissue surgeries. It is generally known that bone surgeries are associated with more severe pain with poor post-operative pain control (Ekstein et al., 2008; Apfelbaum et al., 2003). Furthermore, female sex is negatively correlated to severe to worst pain at both $12^{\text {th }}$ and $24^{\text {th }}$ hours, indicating that females are less likely to get severe to worst pain than men. Similar observations have been reported by Chia et al. (2002), although other studies have reported contrary findings (Thomas et al., 1998; Vivian et al., 2009; Masagati \& Chilonga, 2014). Furthermore, sex difference seen in this study is in disagreement with findings by Paulson et al (1998), who demonstrated that women perceived more intense pain than men. The difference observed could be explained by differences in study population and design.

There was insignificant negative correlation of old age and pain in this study in consonance with Healey et al. (1998), but not with Misagati \& Chilonga (2014). Others however, have reported no relationship (Chia et al., 2002; Munafo \& Stevenson, 2003; Mamie et al., 2004; Rudin et al., 2008; DeCosmo et al., 2008). The observed difference calls for further studies, but it could indicate differences in study methodology, socio-cultural disparity among the study populations, hospital settings and quality of care as suggested earlier. In addition, this could be explained by age difference of pattern and severity of injuries or diseases/conditions, parameters which were not scrutinized in our study.

In this study the use of pethidine and tramadol as the main analgesics is similar to that of Misagati \& Chilonga (2014), but dissimilar to the report by Ramsay (2000) who found an increasing use of opioids. It goes without a say that prescription pattern depends on hospital policy, drug availability and surgeons' person preference. As a practice in our hospital, all of the drugs were prescribed by operating surgeons then given to patients by nurses in wards. Unlike our practice, reports from developed countries indicate that the most common and main method of drug dispensation is patient controlled analgesia (White, 1988).

Despite very high prevalence of severe to worst pain in this study, three quarters of the patients were satisfied by the prescribed pain management, a finding slightly higher than that of Chung \& Lie (2003), but less than that of other authors (Apfelbaum et al., 2003; Lorentzen et al., 2012; Misagati \& Chilonga, 2014). Similar to a suggestion given by Masagati \& Chilonga (2014), we could not provide straight answers as to why patients with severe pain tend to be more satisfied with relatively poor pain management provided, a separate study need to be done to verify this observation, a suggestion shared by Lorentzen et al (2012). We also found similar results when prediction factors were considered. As discussed earlier, men with significant severe pain were paradoxically more satisfied with pain management than women. This observation is not in agreement with most studies (Thomas et al., 1998; Baranovi et al., 2011; Masagati \& Chilonga, 2014). Multiple factors including study methodology, social cultural disparities, and hospital settings, quality of care and pattern/severity of injuries or diseases/conditions may have played a key role in the observed differences.

In conclusion, the prevalence of post-operative pain is very high especially in the first 12hour post-operative period. Paradoxically male sex was a prediction factor of pain management satisfaction. The commonest drugs prescribed were pethidine and tramadol injection. Surgeons therefore need to prioritize analgesic prescription at early hours following operation to minimize pain and suffering to patients focusing on orthopaedic procedures.

\section{Acknowledgements}

Members of surgical department at the TRRH, Head of Department of Surgery and the Hospital Superintendent are acknowledged for their various contributions. The College of Health Sciences 
of the University of Dodoma, deserves a special gratitude, no much could have been done without its support.

\section{Conflict of interests}

Authors declare no conflict of interests.

\section{References}

Apfelbaum, J.L, Connie, C., Mehta, S.S. \& Gan, T.J. (2003) Postoperative Pain Experience: Results from a National Survey Suggest Postoperative Pain Continues to Be Undermanaged. Anesthesia \& Analgesia 97: 534-540.

Bagi, I.A. \& Ahmed, M.E. (1993) Postoperative pain and analgesic prescription in Khartoum: evaluation of current practice. East African Medical Journal 70: 502-505.

Baranovi, S., Milan, M., Lubina, I.Z. \& Maldini, B. (2011) Our experience with femoral analgesia after orthopaedic surgical procedures on lower extremities. Periodicum Biologorum 113: 223227.

Bijur, P.E., Latimer, C.T. \& Gallagher, E.J. (2003) Validation of a Verbally Administered Numerical Rating Scale of Acute Pain for Use in the Emergency Department. Academic Emergency Medicine 10 (4).

Breivik, H. (1998) Postoperative pain management: why is it difficult to show that it improves outcome? European Journal of Anaesthesiology 15:748-51.

Carr, D. \& Goudas, L. (1999) Acute pain. Lancet 353(9169):2051-2058.

Chia, Y.Y., Chow, L.H., Hu, C.C., Liu, K, Ger, L.P. \& Wang, P.N. (2002) Gender and pain upon movement are associated with the requirements for postoperative patient-controlled iv analgesia: a prospective survey of 2,298 Chinese patients. Canadian Journal of Anaesthesiology 49:249-55.

Chou, R., Gordon., D.B, de Leon-Casasola, O.A., Rosenberg, J.M., Bickler, S., Brennan, T., Carter, T., Cassidy, C.L, Chittenden, E.H., Degenhardt, E., Griffith, S., Manworren, R., McCarberg, B., Montgomery, R., Murphy, J., Perkal, M.F., Suresh, S., Sluka, K., Strassels, S., Thirlby, R., Viscusi, E., Walco, GA., Warner, L., Weisman, S.J. \& Wu, C.L. (2016) Management of Postoperative Pain: A Clinical Practice Guideline from the American Pain Society, the American Society of Regional Anesthesia and Pain Medicine, and the American Society of Anesthesiologists' Committee on Regional Anesthesia, Executive. Journal of Pain 17: 131157.

Chung, J.W. \& Lui, J.C. (2003) Postoperative pain management: study of patients' level of pain and satisfaction with health care providers' responsiveness to their reports of pain. Nursing Health Sciences 5:13-21.

De Cosmo, G., Congedo, E., Lai, C., Primieri, P., Dottarelli, A. \& Aceto, P. (2008) Preoperative psychologic and demographic predictors of pain perception and tramadol consumption using intravenous patient-controlled analgesia. Clinical Journal of Pain 24:399-405.

Dolin, S.J., Cashman, J.N. \& Bland, J.M. (2002) Effectiveness of acute postoperative pain management: I. Evidence from published data. British Journal of Anaesthesiology 89:409423.

Ekstein, M., Marouni, N. \& Weinbroum, A. (2008) Incidence of postoperative severe pain is higher after orthopaedic surgery than after laparotomy; ketamine is effective in relieving such pain. European Journal of Anaesthesiology 25:208.

Gan, T.J., Habib, A.S., Miller, T.E., White, W. \& Apfelbaum, J.L. (2014) Incidence, patient satisfaction, and perceptions of post-surgical pain: results from a US national survey. Current Medical Research Opinions 30:149-60. 
Gagliese, L., Weizblit, N., Ellis, W. \& Chan, V.W. (2005) The measurement of postoperative pain: A comparison of intensity scales in younger and older surgical patients. Pain 117:412-420.

Kehlet, H., Jensen, T. \& Woolf, C. (2006) Persistent postsurgical pain: Risk factors and prevention. Lancet 367:1618-1625.

Lennard, T.W., Shenton, B.K., Borzotta, A., Donnelly, P.K., White, M., Gerrie, L.M., Proud, G. \& Taylor, R.M. (1985) The influence of surgical operations on components of the human immune system. British Journal of Surgery 72:771-776.

Lorentzen, V., Hermansen, I.L. \& Botti, M. (2012) A prospective analysis of pain experience, beliefs and attitudes, and pain management of a cohort of Danish surgical patients. European Journal of Pain 16:278-88.

Mamie, C., Bernstein, M., Morabia, A., Klopfenstein, C.E., Sloutskis, D. \& Forster, A. (2004) Are there reliable predictors of postoperative pain? Acta Anaesthesiologica Scandinavica 48:234-242.

Masagati, H.G. \& Chilonga, K.S. (2014). Postoperative pain management outcomes among adults treated at a tertiary hospital in Moshi. Tanzania Journal of Health Research 16(1).

Mbula, K.S. (2010) Comparison of an effort dependent pain assessment tool with the visual analogue score in orthopaedic postoperative patients in Mulago hospital. Masters of Science Dissertation, Makerere University, Uganda.

Munafo, M.R. \& Stevenson, J. (2003) Selective processing of threat-related cues in day surgery patients and prediction of post-operative pain. British Journal of Health Psychology 8:439449.

URT (2013) Population and Housing Census, 2012. National Bureau of Statistics, Dar es Salaam, Tanzania. Available on www.nbs.go.tz

Paulson, P.P., Minoshima, S., Morrow, T.J. \& Caseya, K.L. (1998) Gender differences in pain perception and patterns of cerebral activation during noxious heat stimulation in humans. Pain 76: 223-229.

Ramsay, M.A.E. (2000) Acute postoperative pain management. Proceedings of the Baylor University Medical Centre 13: 244-247

Rudin, A., Wolner-Hanssen, P., Hellbom, M. \& Werner, M.U. (2008) Prediction of postoperative pain after a laparoscopic tubal ligation procedure. Acta Anaesthesiologica Scandinavica 52:93845

Thomas, T., Robinson, C., Champion, D., McKell, M. \& Pell, M. (1998) Prediction and assessment of the severity of post-operative pain and of satisfaction with management. Pain 75: 177-185

Vivian, H.Y., Abrishami, A., Peng, P.W.H., Wong, J. \& Chung, F. (2009) Predictors of postoperative pain and analgesic consumption: a qualitative systematic review. Anesthesiology 11: 657677 .

Xu, X., Li, B., Liu, L. \& Zhao, Y. (2016) Body pain intensity and interference in adults (45-53 years old): a cross-sectional survey in Chongqing, China. International Journal of Environmental Research \& Public Health 13: 887.

White, P.F. (1988) Use of patient-controlled analgesia for management of acute pain. JAMA 259:243-247. 